\title{
Routine CT Angiography in Acute Stroke Does Not Delay Thrombolytic Therapy
}

\author{
Simerpreet Bal, Bijoy K. Menon, Andrew M. Demchuk, Michael D. Hill for the \\ Calgary CTA Study Group
}

\begin{abstract}
Introduction: Lack of additional utility over non-contract computed tomography (NCCT) in decision making and delay in door to needle time are arguments used against routine computed tomographic angiography (CTA) use in acute ischemic stroke management. We compare interval times during a CTA based acute ischemic stroke protocol with an earlier non-CTA based protocol at our center. Methods: We reviewed 850 stroke thrombolysis patients in a university hospital in Canada from April 1996 to December 2009. Time to treatment was divided into the following interval times: onset-to-door, door-to-needle and onset-to-needle. Patients were categorized into: Group 1 (April 1996 -Dec 2002) (Non-contrast CT Scan based thrombolysis) n=297, Group 2 (Jan 2004- Dec 2009) (CTA based thrombolysis) $n=504$. The period from Jan to Dec $2003(n=49)$ was considered a washout period as we had started the CTA protocol that year. Interval times were compared between the two groups. Results: Interval times in Group 1 and Group 2 were: median onset-to-door times in Group 1 [55 minutes (IQR 48),] and Group 2 [61 minutes (IQR 57)] (p=0.019); median door-to-needle times in Group 1 [67 minutes(IQR 43)] and Group 2 [62.5 minutes (IQR 52)] (p=0.519); median onset-to-needle times in Group 1 (139 minutes (IQR 73)] and Group 2 (141.5 min (IQR 109.5) ( $\mathrm{p}=0.468)$. In multivariable linear regression analysis, age and onset-to-door time influenced the door-to-needle time. For every decade of age, door-to-needle times were 5.4 minutes faster. Conclusions: CTA based thrombolytic approach for acute ischemic stroke does not significantly delay thrombolysis in routine clinical practice.
\end{abstract}

RÉSUMÉ: L'angiographie par tomodensitométrie dans l'accident vasculaire cérébral aigu ne retarde pas le traitement par thrombolyse. Contexte : L'absence d'avantage supplémentaire de l'angiographie par tomodensitométrie (ACT) par rapport à la tomodensitométrie sans contraste dans la prise de décision et la prolongation du temps de l'arrivée à l'hôpital à l'injection sont des arguments qui sont utilisés contre l'utilisation de routine de l'ACT dans le traitement de l'accident vasculaire cérébral ischémique aigu (AVCIA). Nous avons comparé les délais au cours d'un protocole basé sur l'ACT dans l'AVCIA avec ceux observés au cours d'un protocole antérieur non basé sur l'ACT dans notre centre. Méthode : Nous avons révisé les dossiers de 850 patients atteints d'un AVC qui ont subi une thrombolyse dans un hôpital universitaire du Canada entre avril 1996 et décembre 2009 . Le temps écoulé du début des symptômes jusqu'au moment du traitement a été réparti en 3 phases : du début des symptômes jusqu'au moment où le patient arrive à l'hôpital, de l'arrivée à l'hôpital au moment de l'injection et du début des symptômes au moment l'injection. Les patients étaient répartis en deux groupes : le groupe 1, d'avril 1996 à décembre 2002, constitué de patients dont la thrombolyse était basée sur une tomodensitométrie sans contraste (n = 297) et le groupe 2, de janvier 2004 à décembre 2009, constitué de patients dont la thrombolyse était basée sur une ACT (n = 504). La période de janvier à décembre $2003(\mathrm{n}=49)$ a été considérée comme une période sans traitement parce que nous avons commencé le protocole ACT cette annéelà. Nous avons comparé les délais entre les deux groupes. Résultats : Les délais dans le groupe 1 et le groupe 2 étaient les suivants : le temps médian du début des symptômes à l'arrivée à l'hôpital dans le groupe 1 était de 55 minutes (intervalle interquartile (IQR) 48) et dans le groupe 2 il était de 61 minutes (IQR 57) (p = 0,019); la médiane du délai de l'arrivée à l'hôpital jusqu'au moment de l'injection dans le groupe 1 était de 67 minutes (IQR 43 ) et dans le groupe 2 de 62,5 minutes (IQR 52) ( $\mathrm{p}=0,519)$; le temps médian du début des symptômes jusqu'au moment de l'injection dans le groupe 1 était de 139 minutes (IQR 73) et dans le groupe 2 de 141,5 minutes (IQR 109,5) (p = 0,468). L'analyse de régression linéaire multivariée a montré que l'âge et le temps écoulé entre le début des symptômes et l'arrivée à l'hôpital influençaient le délai entre l'arrivée à l'hôpital et l'injection. Le temps écoulé de l'arrivée à l'hôpital à l'injection était plus court de 5,4 minutes pour chaque décennie supplémentaire d'âge du patient. Conclusions : Pour la thrombolyse, l'approche basée sur l'ACT dans l'AVCIA ne retarde pas significativement la thrombolyse en pratique clinique courante.

Can J Neurol Sci. 2012; 39: 499-501

Brain imaging, most commonly with non-contract computed tomography (NCCT), is mandatory before stroke thrombolysis. ${ }^{1}$ Adding computed tomographic angiography (CTA) to NCCT can quickly and reliably add valuable vascular information that can be immediately used to triage the patient to the best possible therapy. However, time-to-treatment must be minimized to promote the best possible outcomes. ${ }^{2}$ Computed tomographic angiography has been criticized because of concerns over the time needed to image and interpret the results. In practice, first review of CTA is undertaken by the stroke neurologist and stroke fellow and involves careful review of both the reformatted and original images. With modern CT imaging technology the imaging time is short, usually a few minutes, but the time taken to prepare the patient, obtain a baseline serum creatinine level and then process, reformat and interpret the imaging may take

From the Calgary Stroke Program, Department of Clinical Neurosciences, (SB, BKM, AMD, MDH) Department of Radiology (AMD), Hotchkiss Brain Institute, University of Calgary, Calgary, Alberta, Canada.

Received December 14, 2011. Final Revisions Submitted January 25, 2012. Correspondence to: Michael D. Hill, Calgary Stroke Program, Department of Clinical Neurosciences, Hotchkiss, Brain Institute, University of Calgary, Foothills Hospital, Rm 1242A, 1403 29th Street NW, Calgary, Alberta, T2N 2T9, Canada.

Email: michael.hill@ucalgary.ca 
much longer. We assessed the overall times-to-treatment using both a NCCT based approach and a NCCT plus CTA-based approach to acute brain imaging.

\section{Materials ANd Methods}

Calgary provides tertiary stroke care to a catchment population of about 1.4 million people. The Calgary Health Region and the Conjoint University of Calgary and Calgary Health Region Ethics Board gave special permission in early 1996, prior to Health Canada approval, for the use of open-label intravenous alteplase for acute ischemic stroke. The first Calgary patient with acute ischemic stroke was thrombolysed on the 2nd April 1996. ${ }^{3}$ In the time period from April 1996 until December 2009 , there was gradual increase in the number of patients with stroke who were treated with thrombolytic therapy. Acute CTA became available locally in 2003. Initially, it was used intermittently at the judgment of the attending stroke team; thereafter NCCT\CTA head and neck has been a protocol for all acute stroke patients admitted in the emergency department.

The Calgary Stroke Program maintains a database of all stroke patients who undergo acute CTA and who receive thrombolysis (pharmacological and/or endovascular mechanical). Computed tomographic angiography in the assessment of acute stroke syndromes is routine but not default practice at our site; pragmatically however, this has meant that $95 \%$-plus of our patients now undergo CTA hyperacutely as part of their initial imaging paradigm

We reviewed our stroke database for patients who have received thrombolytic therapy from April 1996 to December 2009. Eleven hundred and thirty seven patients received thrombolytic therapy during this period. Patients with indications other than acute ischemic stroke, poor quality imaging, incomplete information regarding times for admission, times for treatment and follow up details were excluded and 850 patients treated with thrombolytic therapy (IV and IV plus endovascular intervention) during this period with complete data were included in the final analysis. Time to treatment was divided into the following interval times: onset-to-door, door-to- needle and onset-to-needle. Patients were categorized into two groups by time epoch: Group 1 (April 1996 - Dec 2002) (NCCTbased thrombolysis) n=297, Group 2 (Jan 2004 - Dec 2009) (NCCT plus CTA based thrombolysis) $n=504$. The period from Jan to Dec 2003 ( $n=49)$ was considered a washout period due to the intermittent use of CTA and not included.

Data were analyzed using frequency tables. Comparisons of proportions were made using Fisher's exact test, comparisons between continuous variables were made using a student's t test. Interval times were compared between the two groups using non-parametric test of medians and by multiple linear regression. Using multiple linear regression, we assessed whether clinical characteristics confounded this comparison of interval times. All the statistical analysis was done with STATA Version 10.

\section{RESULTS}

Eight hundred and one patients were included in the final analyses. The two cohorts were matched for age (median 73), sex (52\% male), baseline serum glucose. The Group 2 cohort had slightly less severe stroke (median NIHSS 13 compared to 16) and concurrently a slightly greater proportion of partial anterior circulation syndromes. Median onset to door times were six minutes longer in Group 2 compared to Group 1. [see Table] Door-to-needle times were similar in both groups. In multivariable linear regression analysis, age and onset-to-door time influenced the door-to-needle time. For every decade of age, door-to-needle times were 5.4 minutes faster. For every 30 minutes delay in onset-to-door time, there was a 4.0 minute delay in door-to-needle time. There was no evidence of an effect of time epoch. There was no evidence of interaction between age and time epoch or onset-to-door time and time epoch.

\section{DiscusSION}

On average, the addition of CTA to a NCCT imaging paradigm does not delay therapy. However, there is a high interpatient variance in door-to-needle times. This variance is driven by patient factors such as the need to obtain laboratory results,

Table: Treatment times in patients with acute ischemic stroke treated with thrombolytic therapy in different time periods from 1996-2009. Also shown is the multivariable analysis of predictors of door to needle times in all the patients.

\begin{tabular}{|c|c|c|c|}
\hline & $\begin{array}{l}\text { Group } 1 \text { (April 1996- } \\
\text { December 2002) }\end{array}$ & $\begin{array}{l}\text { Group } 2 \text { (January } \\
\text { 2004-December 2009) }\end{array}$ & $\underline{P \text {-value }}$ \\
\hline Onset-to-door time (median(IQR) & $55(48)$ & $61(57)$ & 0.01 \\
\hline Door to needle time(median(IQR) & $67(43)$ & $62.5(42)$ & 0.51 \\
\hline Door to needle time(median(IQR) & $139(71)$ & $141.5(109.5)$ & 0.46 \\
\hline \multicolumn{4}{|c|}{ Multivariable Linear Regression Analysis: Predictors of Door-to-needle time* } \\
\hline \multicolumn{4}{|c|}{ B-coefficient } \\
\hline Age & -0.54 & & $<0.001$ \\
\hline Onset-to-door time & 0.13 & & $<0.001$ \\
\hline Group 1 v. Group 2 & -1.75 & & 0.506 \\
\hline
\end{tabular}

* Adjusted for sex and bNIHSS 
and likely by decision making processes by the attending stroke team. Our results could be confounded by improvements over time within our stroke program. The before-after cohort design of the study does not allow us to assess the role that quality improvement activities have played in improving our overall interval times. These improvements may have obscured any detrimental effect introduced by the routine use of CTA. Further, while we believe it unlikely, it is possible that delays incurred due to CTA might have resulted in a decision not to offer thrombolysis and therefore exclusion of patients, biasing the result in favour of the hypothesis.

If CTA does not substantially delay therapy, a key question is what value does it add? We have found that we use CTA to: (a) triage patients immediately to additional endovascular therapy when they have proximal vessel occlusion and to plan an endovascular approach with knowledge of the aortic arch, the extracranial vessels and the circle of Willis; ${ }^{4}$ (b) to assess collateral circulation ${ }^{5}$ (c) to assess the risk of progression to malignant middle carotid artery (MCA) infarction and in parallel predict the need for early hemicraniectomy; ${ }^{6}$ (d) to make an inclusive diagnosis of ischemic stroke when the NCCT is normal and to exclude stroke mimics. ${ }^{7-9}$ Inherent in a decision to use CTA is very rapid access to or expertise in interpretation.

Interestingly older patients were treated slightly faster irrespective of whether CTA was used or not. Overall, CTA does not delay therapy to significant extent when implemented within a comprehensive stroke thrombolysis program.

\section{REFERENCES}

1. Practice advisory: Thrombolytic therapy for acute ischemic stroke-summary statement. Report of the quality standards subcommittee of the American Academy of Neurology. Neurology. 1996;47:835-9.

2. Shrier DA, Tanaka H, Numaguchi Y, Konno S, Patel U, Shibata D. $\mathrm{Ct}$ angiography in the evaluation of acute stroke. AJNR Am J Neuroradiol. 1997; 18:1011-20.

3. Hill MD, Barber PA, Demchuk AM, et al. Building a "brain attack" team to administer thrombolytic therapy for acute ischemic stroke. CMAJ. 2000;162:1589-93.

4. Lev MH, Nichols SJ. Computed tomographic angiography and computed tomographic perfusion imaging of hyperacute stroke. Top Magn Reson Imaging. 2000;11:273-7.

5. Menon BK, Smith EE, Modi J, et al. Regional leptomeningeal score on ct angiography predicts clinical and imaging outcomes in patients with acute anterior circulation occlusions. AJNR Am J Neuroradiol. 2011;32:1640-5.

6. Menon BK, Bal S, Modi J, et al. Anterior temporal artery sign in ct angiography predicts reduced fatal brain edema and mortality in acute M1 middle cerebral artery occlusions. J Neuroimaging. 2012 Apr;22(2):145-8. doi: 10.1111/j.1552-6569. 2010. 00566.x. Epub 2011 Jan 11

7. Schramm P, Schellinger PD, Fiebach JB, et al. Comparison of ct and ct angiography source images with diffusion-weighted imaging in patients with acute stroke within 6 hours after onset. Stroke. 2002;33:2426-32.

8. Coutts SB, Lev MH, Eliasziw M, et al. Aspects on CTA source images versus unenhanced CT: added value in predicting final infarct extent and clinical outcome. Stroke. 2004;35:2472-6.

9. Ledezma CJ, Wintermark M. Multimodal CT in stroke imaging: new concepts. Radiol Clin North Am. 2009;47:109-16. 